\section{Intersections}

Canadian Journal of Music

Revue canadienne de musique
Intersections CANADIAN JOURAL OR MUSIO

\title{
Closure in Classical Themes: The Role of Melody and Texture in Cadences, Closural Function, and the Separated Cadence
}

\section{Mark Richards}

Volume 31, numéro 1, 2010

Contemplating Caplin

URI : https://id.erudit.org/iderudit/1009283ar

DOI : https://doi.org/10.7202/1009283ar

Aller au sommaire du numéro

Éditeur(s)

Canadian University Music Society / Société de musique des universités canadiennes

ISSN

1911-0146 (imprimé)

1918-512X (numérique)

Découvrir la revue

Citer cet article

Richards, M. (2010). Closure in Classical Themes: The Role of Melody and Texture in Cadences, Closural Function, and the Separated Cadence. Intersections, 31(1), 25-45. https://doi.org/10.7202/1009283ar
Résumé de l'article

Cet article remet en question deux des postulats de base William E. Caplin concernant les cadences dans le style classique. Tout d'abord, l'auteur fait valoir que la mélodie et la texture aident à délimiter la fonction cadentielle. Il soutient ensuite que tant la demi-cadence que la cadence authentique peuvent marquer la fin d'un thème, tout comme peut le faire une " fonction conclusive ", qui se substitue à la fonction cadentielle par une " progression quasi cadentielle ». En outre, il explique comment une cadence peut conclure un thème de telle sorte que sa mélodie et sa basse se résolvent à différents moments, un phénomène qu'il appelle la cadence séparée.
All Rights Reserved @ Canadian University Music Society / Société de musique des universités canadiennes, 2012
Ce document est protégé par la loi sur le droit d'auteur. L'utilisation des services d'Érudit (y compris la reproduction) est assujettie à sa politique d'utilisation que vous pouvez consulter en ligne.

https://apropos.erudit.org/fr/usagers/politique-dutilisation/ 


\title{
CLOSURE IN CLASSICAL THEMES: THE ROLE OF MELODY AND TEXTURE IN CADENCES, CLOSURAL FUNCTION, AND THE SEPARATED CADENCE
}

\author{
Mark Richards
}

Renowned Haydn scholar James Webster once proclaimed that "the sense of closure is arguably the most essential structural attribute of tonal music" (Webster 1991, 145). This is especially true of the classical style, where the attainment of closure at the end of phrases and themes marks a goal toward which this music often seems to have an inexorable drive. But while most of us could probably agree on where a cadence ends, where it begins is another matter, because the number of harmonies preceding its end may vary significantly. Moreover, some themes and phrases end without a half or authentic cadence, yet still provide a weaker form of harmonic closure. These "grey" areas of formal analysis serve as the subject of this paper, which explores three different aspects of closure in classical themes: (1) the role of melody and texture in defining cadences; (2) a type of ending I call a "closural function," which substitutes for a cadence; and (3) a concept I term the "separated cadence," which clarifies the location and type of cadence in some unusual situations.

\section{The Role of Melody and Texture in Cadences}

William Caplin $(1998 ; 2004)$ has recently defined the cadence according to two essential parameters: location within a phrase and harmonic progression. As for its location, a cadence must form an ending "to something." That is, a cadence is always preceded by a separate initiating structural unit, at the very least a two-measure unit that Caplin calls a "basic idea." Harmonically, a cadence must encompass a cadential progression which, in its complete form, contains an initial tonic, predominant, dominant, and final tonic-the latter two always occurring in root position (Caplin 2004, 57, 70). ${ }^{1}$ If these two criteria are met, the result is a genuine cadence, or a span of music that serves a "cadential function" in Caplin's terminology. Thus, apart from distinguishing between perfect and imperfect authentic cadences, melody does not contribute to Caplin's notion of cadential function, nor does it play a significant role in his theory overall. He maintains, for instance, that "contrary to common opinion, the formal function of an individual group does not depend on its

1 This definition of a complete cadential progression has also been posited by Schmalfeldt $(1992,3)$. 
motivic content" $(1998,4) .{ }^{2}$ Certainly, this claim places a necessary distance between Caplin's theory of form and those based on Schoenbergian notions of "developing variation," which emphasize motivic content. At the same time it downplays the importance of motivic and textural change, an aspect of form that plays a significant role in the identification of formal functions. ${ }^{3}$

In example 1a, for instance, the distinction between the first basic idea and the second is made clear by the repetition of the melodic content. In other words, when the idea begins to repeat, we perceive a separation between the two ideas and are able to distinguish one basic idea from the next. In example $1 b$, the basic idea in mm. 1-2 and 5-6 is separated by the following two measures-a "contrasting idea"-punctuated in m. 2 with a melodic halt on an eighth note and an ensuing eighth rest (in addition to the quarter rest in the left hand). And finally, in example 1c, the continuation function of a sentence is defined by fragmentation, or a shortening of the structural units. These shorter units are discernible only because of the repetition of one-measure groups in the melody. Thus, changes in melodic material and texture can signal that a new formal function is underway. The initiation of cadential functions are generally signalled by such melodic/textural changes in addition to a cadential progression located at the end of the phrase. Melodically, these changes are determined by alterations in rhythm, motive, direction, or type of motion (steps versus skips), and texturally by contrasts in figuration, accompaniment, dynamic, articulation, timbre, or number of voices.

To understand how changes in melody and texture affect the location of a cadential function, I refer to the opening theme from the slow movement of Mozart's Piano Sonata in C Major, K. 330, shown in example 2. The theme is structured as an "antecedent + continuation," or Caplin's hybrid $1(1998,59)$. Caplin (6o) locates the start of the cadential function at m. 7, which is uncontroversial since the antecedent functions as the initiating unit and the $\mathrm{ii}^{6}$ chord is part of a cadential progression. But one might ask why the cadence does not begin with the $\mathrm{I}^{6}$ chord in $\mathrm{m}$. 6, especially since Caplin considers that chord to be a "conventionalized sign" for the onset of cadential function (Caplin 1987, 218). I would argue that tonic chords are weak indicators of cadential function because essentially any chord can follow them, whereas predominant and dominant chords are strong indicators because only certain chords are expected to follow them. Thus, in order for a tonic chord to initiate cadential

2 See also Schmalfeldt $(1997,110)$, who makes a similar plea: "To this day, the post-Schoenbergian formalist's taxonomy of theme-types is commonly mistaken for thematicism, a term chiefly associated with tracing repetitions and recurrences of melodic structures qua motives. That motivic criteria play, at best, only a subordinate role in the determination of theme-types, cannot be emphasized strongly enough."

3 Hepokoski $(2009,42-43)$ has recently argued that melodic and textural changes play a larger role in classical form than Caplin allows: "What is one to make of any system that declares that 'thematic content,' a central topical feature of the dramatized classical style by any account and one of the foremost attributes that all listeners directly experience, 'plays [only] a minimal role' when compared with ever-recurring strings of beginning-middle-end functionalities? The dramatic textural contrasts and intertextually shared thematic/topical signs that such content regularly provides as vivid, expressive hallmarks of the style are thus demoted to a status 'essentially independent of formal functionality,' with 'no necessary connection to formal function."' 


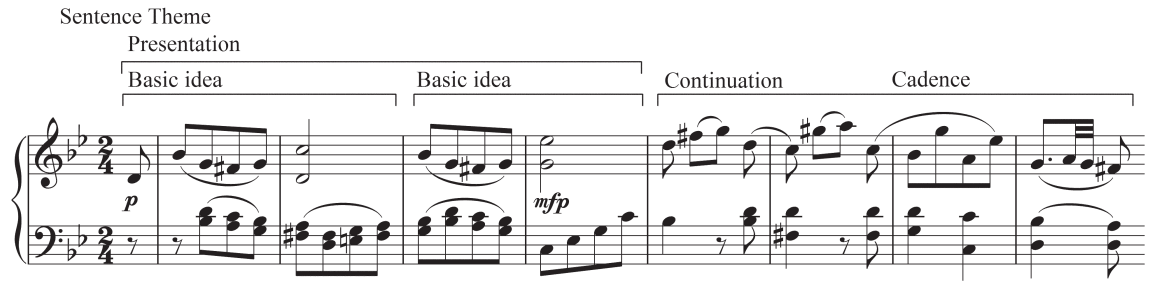

Period Theme

ANTECEDENT

Basic idea

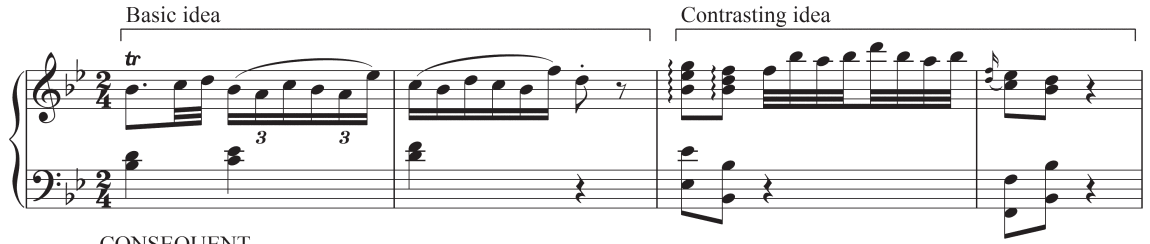

CONSEQUENT

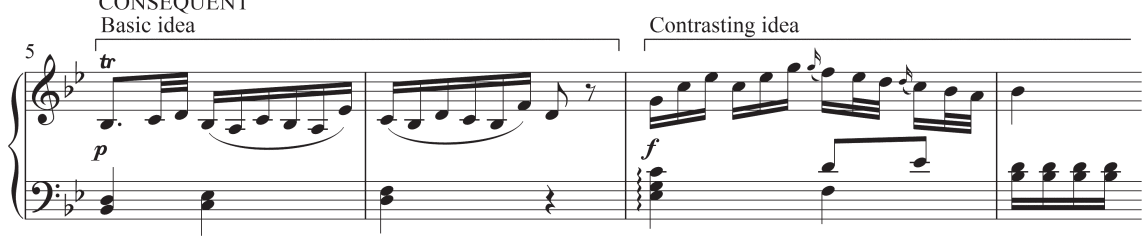

Sentence Theme Presentation

Basic idea

Continuation fragmentatior

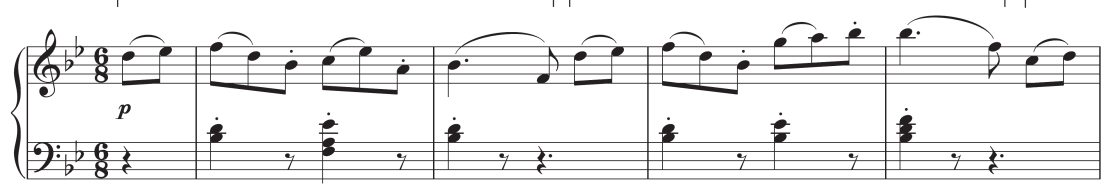

Cadence

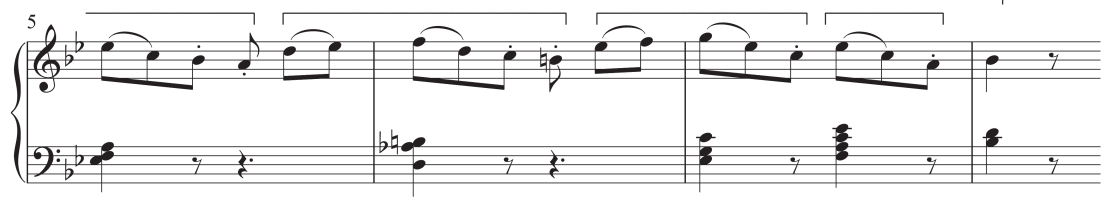

Example 1. Changes of melody and texture in the distinction between formal functions

a. Basic idea: Beethoven, Piano Sonata in G Minor, op. 49 no. 1, mm. 1-8

b. Contrasting idea: Mozart, Piano Sonata in B-Flat Major, K. 281, mm. 1-8

c. Continuation: Haydn, Symphony No. 98 in B-Flat Major, IV, mm. 1-8 

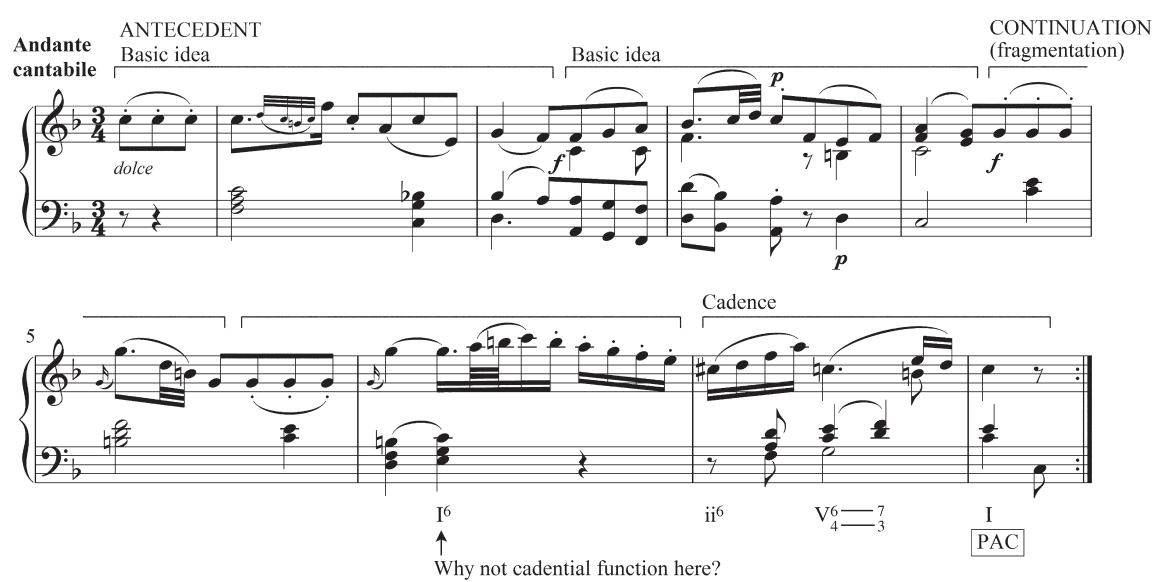

Example 2. Cadential function beginning after an initial tonic chord: Mozart, Piano Sonata in C Major, K. 330, II, mm. 1-8

function, it must be accompanied by a change in melody or texture to express the beginning of a new formal function at that point. In example 2 , the $\mathrm{I}^{6}$ chord supports a melodic figure that begins in the previous measure and therefore, lacking a change in melody or texture, cannot form the start of the cadential function. At m. 7 , however, the melody changes from a falling staccato scale to a rising legato arpeggio, and hence the three criteria of location, harmony, and melody/texture are all fulfilled. 4

In some cases, a predominant chord may not be considered part of the cadential function, even if it is part of a cadential progression, because it lacks melodic or textural articulation, as in the opening theme from the finale of Beethoven's Piano Sonata in A Major, op. 2, no. 2, shown in example 3. In the consequent phrase of this period, the cadential predominant chord occurs as the second measure of a basic idea. Because this basic idea is the initiating unit of the phrase, the cadential function can begin only once it has completed. Hence, although a cadential progression begins in $\mathrm{m} .6$ with the predominant chord, the cadential function does not begin until a new melodic group sounds at $\mathrm{m} .7$ with the dominant six-four chord.

Melodic and textural changes often help to mark the start of a cadential function when a dominant or predominant chord embellishes the initial tonic chord. In these situations, the initial tonic appears to occur late in relation to the start of the cadential function. Embellishing dominant chords usually take the form of a $V_{2}^{4}$, or possibly $V_{3}^{4}$ (Caplin 1987, 241) on account of their resolution to $\mathrm{I}^{6}$, which is the most common form of initial tonic in a cadential function (Caplin 1998, 27). An initial tonic in root position is certainly not uncommon, however, as one frequently encounters a $\mathrm{V}_{5}^{6}\left(\right.$ or $\left.\mathrm{V}_{3}^{4}\right)$ embellishing a root-position

4 This instance of the initial tonic chord of a cadence occurring too early to be included in the cadential function is a particularly common situation in the classical repertoire. Other examples include Mozart, Piano Sonata in A Major, K. 331, m. 4, and Haydn, Piano Sonata in C Major, Hob. XVI: $50, \mathrm{~m}$. 10. In both cases, the cadential function begins with the ensuing $\mathrm{ii}^{6}$ chord. 


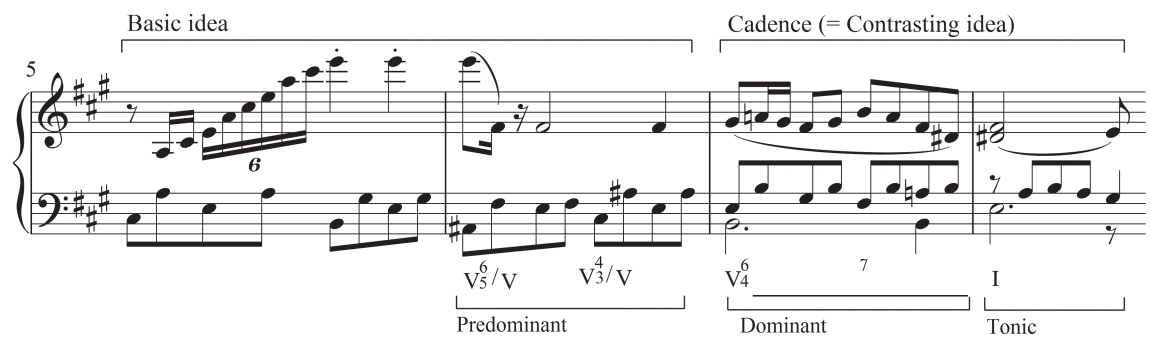

Example 3. Cadential function beginning after a predominant chord: Beethoven, Piano Sonata in A Major, op. 2, no. 2, mm. 5-8

tonic in cadential functions. 5 In the opening theme from Mozart's Piano Sonata in B-Flat Major, K. 333, shown in example 4, the theme is organized as a sentence with a four-measure presentation, a repeated two-measure continuation (defined by fragmentation and rhythmic acceleration), and a two-measure cadential function that is distinct from the foregoing continuation. Note especially the change in texture from one to three voices, and the change in melodic material from rapid sixteenth notes to a form of the syncopated motive that began the continuation at $\mathrm{m}$. 5. These features, along with the cadential progression and the fact that there is a preceding initiating function (the presentation), clearly mark the start of the cadential function on a $V_{5}^{6}$ that embellishes the initial I chord.

Melody and texture also aid in determining the start of larger-scale cadential functions, especially those in which a potentially cadential tonic or predominant chord is prolonged and hence seems to permit more than one possibility for the start of cadential function. When, for instance, a tonic chord is prolonged through the progression $\mathrm{I}-\mathrm{V}_{3}^{4}-\mathrm{I}^{6}$ (or, conversely, $\mathrm{I}^{6}-\mathrm{V}_{3}^{4}-\mathrm{I}$ ) then proceeds to cadential predominant and dominant chords, it can be difficult to locate the start of the cadential function since both I and $\mathrm{I}^{6}$ may serve as the initial tonic chord in a cadential function. In such cases, melody and texture are decisive factors. Example 5 shows the latter portion of the second theme from the first movement of Beethoven's Fifth Symphony. In m. 83, fragmentation signifies a continuation function that persists until the end of the theme at m. 110, where there is a perfect authentic cadence. But where does the cadential

5 This type of embellishment is found with some frequency in the classical repertoire. For example, see Haydn, Piano Sonata in A Major, Hob. XVI: 30, II (Tempo di Menuet), mm. 7-8 (here the implied $V_{5}^{6}$ embellishes the initial tonic on the following beat) and the String Quartet in E Major, op. 54, no. 3, IV, mm. 7-8 (note that the $\mathrm{V}_{5}^{6}$ follows a longer melodic note and therefore denotes the start of cadential function). Mozart seems to have preferred the $V_{3}^{4}$ variant of the embellishment: see the String Quartet in F Major, K. 168, III, mm. 3-4, where the V $\mathrm{V}_{3}^{4}$ embellishes and prolongs the preceding initial tonic chord into the following one. See also the String Quartet in A Major, K. 169, IV, mm. 3-4 (where the melodic leap up a fourth signifies the start of cadential function): the Piano Sonata in C Major, K. 309, III, mm. 7-8 (where the vii ${ }^{06}$ prolongs the preceding root-position tonic into the following one), and the Piano Sonata in A Minor, K. 310, III, mm. 7-8. Beethoven seems to have been especially fond of the $V_{5}^{6}$ type of embellishment as a formula for half cadences. See, for example, the following Piano Sonatas: A Major, op. 2, no. 2, II, mm. 3-4; C Minor, op. 10, no. 1, II, mm. 7-8; and D Major, op. 10, no. 3, III, mm. 5-7. See also Beethoven's Symphony No. 2, II, mm. 3-4. 

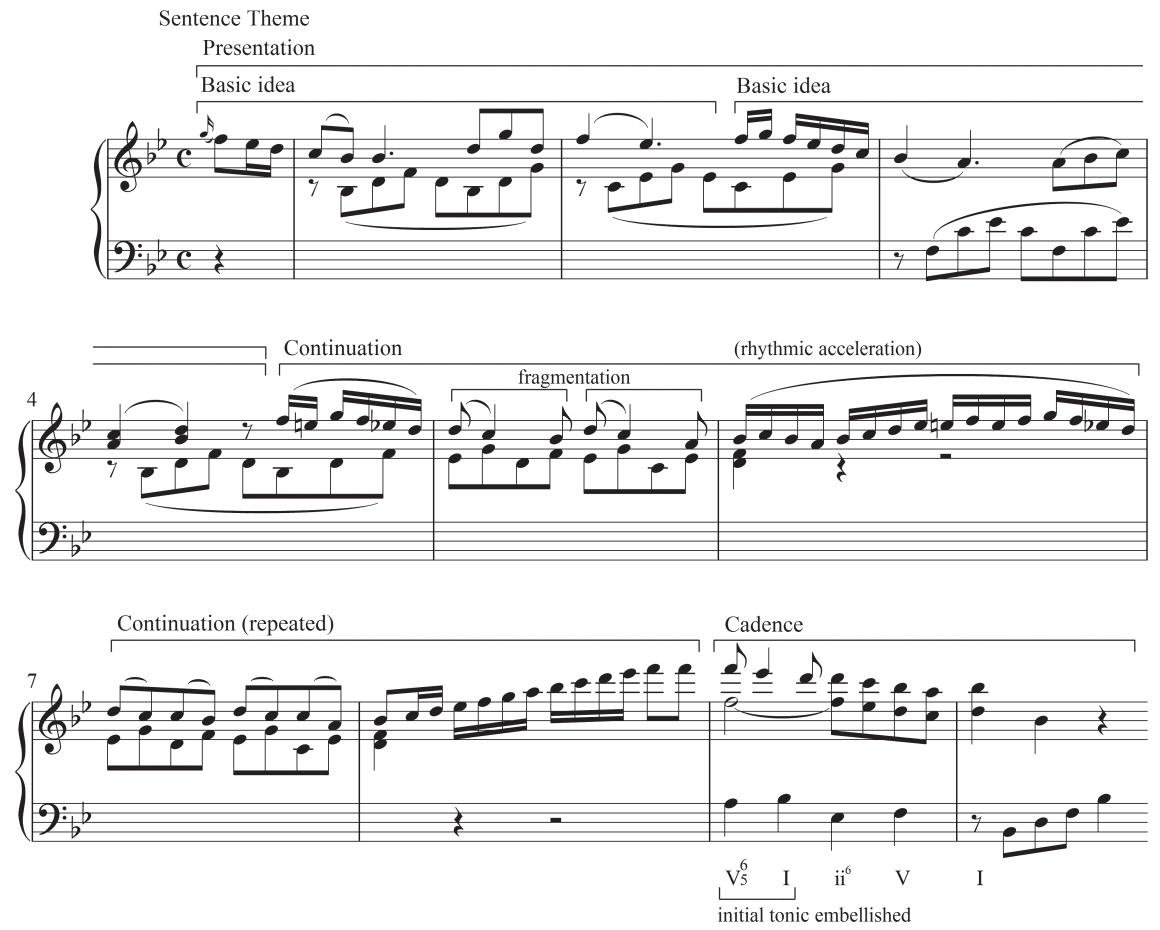

Example 4. Cadential initial tonic chord embellished by a V5 chord: Mozart, Piano Sonata in B-Flat Major, K. 333, mm. 1-10
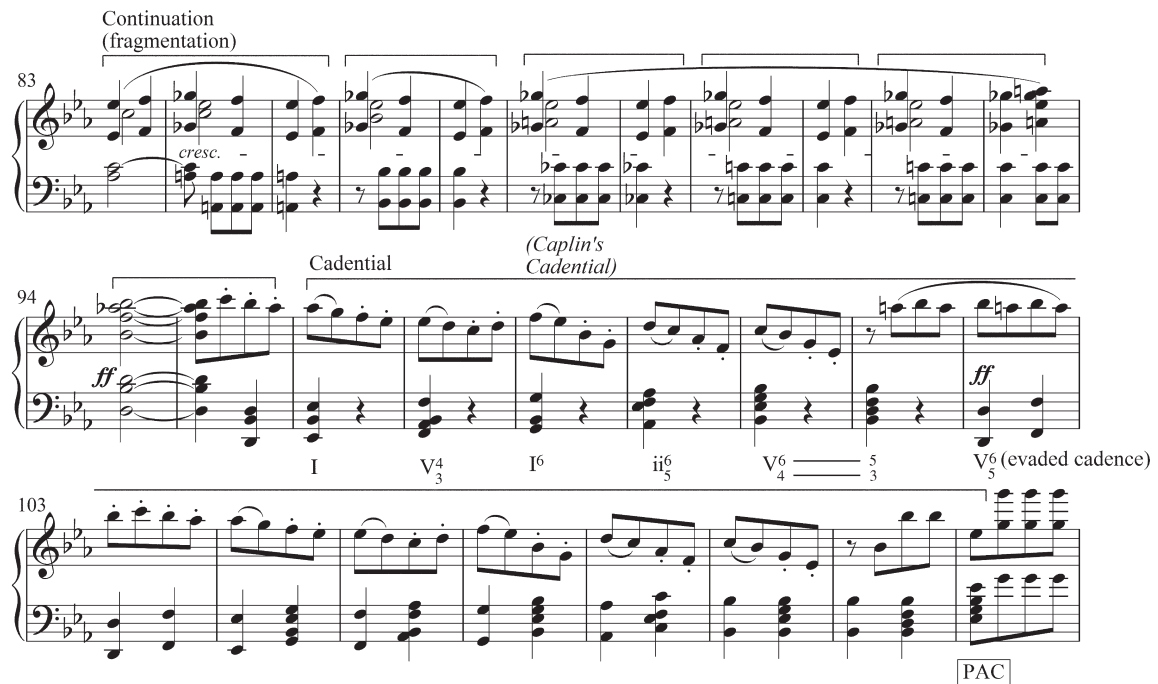

Example 5. Cadential initial tonic chord prolonged by a $V_{3}^{4}$ chord: Beethoven, Fifth Symphony, op. $67, \mathrm{~mm} .83-110$ 
function begin? Caplin (1991, 30-31) identifies the cadence as starting at m. 98 on account of the $\mathrm{I}^{6}$ chord. Notice, however, that there is no melodic or textural change to signal a new formal function at this point; only the location in the phrase and harmonic progression support this interpretation. The stream of eighth notes in the melody actually begins two measures earlier in $\mathrm{m} .96$. The previous measure, which also contains the eighths, acts only as a pickup to the first complete measure of eighth notes. Moreover, the texture of the accompaniment changes at m. 96 from sustained chords to detached chords, and the harmony begins with the tonic-prolonging progression $\mathrm{I}_{-} \mathrm{V}_{3}^{4}-\mathrm{I}^{6}$. Hence, the cadential function begins at $\mathrm{m} .96$, since that measure satisfies the three elements of location within the phrase, harmonic progression, and melodic/textural articulation. This interpretation is further reinforced by the change in mode at m. 96 from the darkness of E-flat minor to a sunny E-flat major.

As demonstrated by the examples above, melodic and textural changes in the classical repertoire are in no way inert in formal functionality, but actively participate in the expression of cadential function. As a result, cadential function may begin in the midst of an ongoing cadential progression, after an initial tonic or even a predominant chord. Alternatively, the initial tonic may be preceded by an embellishing chord, generally an inverted V7. Finally, melody and texture can help to distinguish the start of cadential function when its initial chord (usually tonic) is prolonged by an intervening chord.

\section{Closural Function}

Most themes in the classical repertoire end with either a half or authentic cadence, but some do not. ${ }^{6}$ They may, for instance, end on a $\mathrm{V}$ chord that is inverted, contains a dissonant seventh, or is approached by a dominant pedal. As Caplin $(1998,25 ; 2004,70)$ has clarified, these situations do not constitute half cadences. Likewise, if the theme ends on a I chord, there is no cadence if it is approached by an inverted form of $\mathrm{V}$ or a tonic pedal. Thus, a root-position $\mathrm{V}$ chord is crucial to the concept of cadence in the classical style. 7 Yet even when themes or individual phrases lack a true cadence, a sense of closure is almost always granted by a final I or $\mathrm{V}$ chord that is approached by a cadence-like progression, a series of chords that, but for an inversion of $\mathrm{V}$, an ending on $\mathrm{V} 7$, or a pedal point, would otherwise be cadential. These themes therefore contain a

6 Caplin $(1998,257)$ stipulates that a theme must always end with a cadence. This idea stems from Arnold Schoenberg $(1967,59)$, who states that "the end of a sentence calls for the same treatment as the consequent of a period. A sentence may close on I, V or III, with a suitable cadence." Thus, Schoenberg makes it clear that a cadence is required at the end of the two theme types that he acknowledges, the sentence and the period. This cadential requirement was also carried forth by Schoenberg's pupil, Erwin Ratz $(1973,21)$.

7 It is worth underscoring here that the notion that an inverted $\mathrm{V}$ cannot produce a cadence is only in accordance with Caplin's definition outlined earlier. Other recent sources identify inverted V-I progressions as imperfect authentic cadences. See, for instance, Clendinning and Marvin (2011, 246), and Kostka and Payne $(2000,158)$. Nevertheless, I would agree with Caplin that, within the confines of the classical style, cadences are sounded with a root-position V chord. Holding firmly to this idea exposes the relative rarity of closural functions and draws attention to their expressive effect and formal significance when employed. 

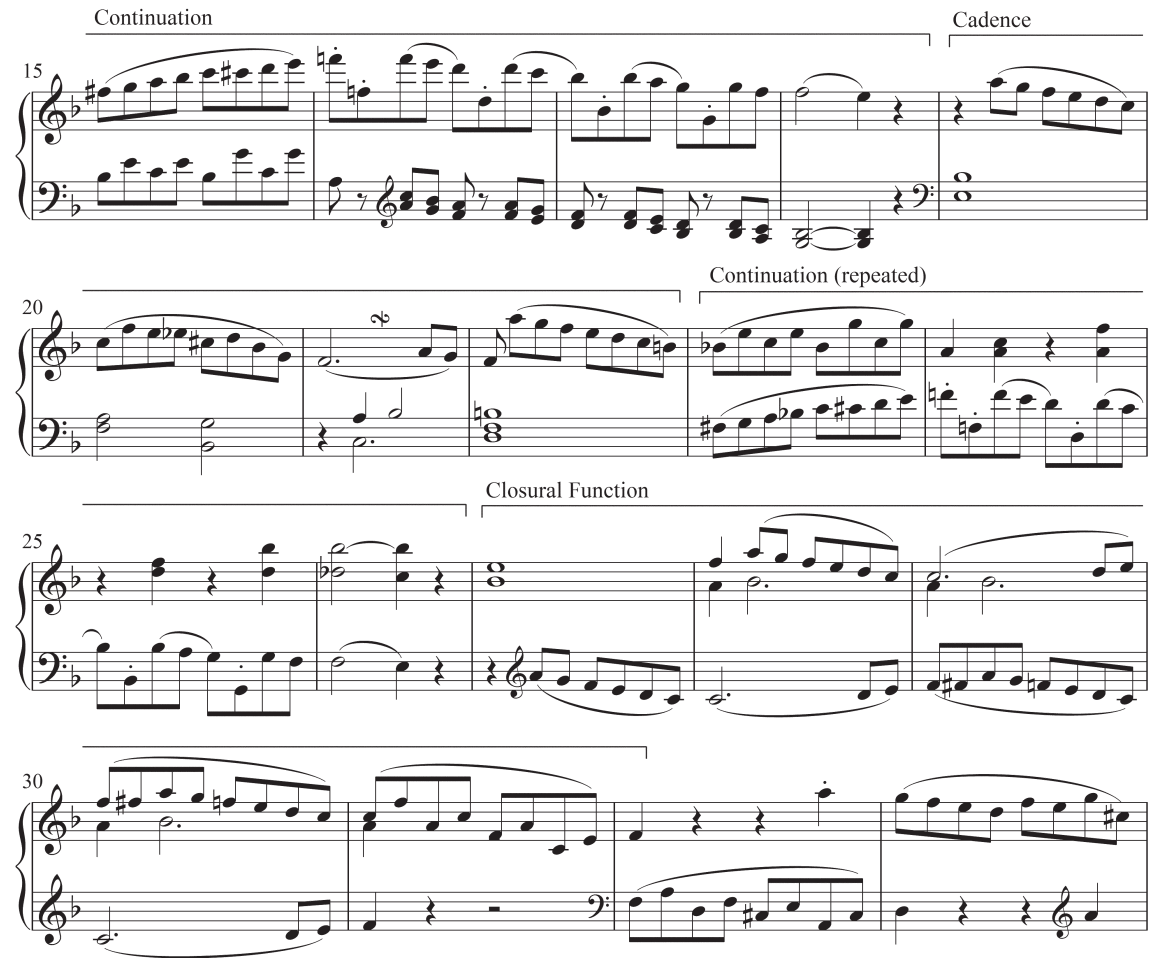

Example 6. Closural function ending the first theme in Mozart's Piano Sonata in F Major, K. $533, \mathrm{~mm} .15-33$

type of form-functional ending that I call a "closural function" or more simply a "close" (as analogies to the terms "cadential function" and "cadence"). The two possible final chords for a closural function, $\mathrm{V}$ or I, yield two different subtypes. First, there is the "dominant arrival," a term coined by Caplin (1998, 79) to describe an ending on a non-cadential V chord within theme-like units. ${ }^{8}$ Second, there is the "tonic arrival," a term that can be used to describe a similar ending on a non-cadential I chord. ${ }^{9}$

A closural function appears in the first movement of Mozart's Piano Sonata in F Major, K. 533 (see example 6). At m. 19, the first theme seems to be approaching its end with the onset of a cadential function, but the final tonic chord that is expected at m. 22 is replaced with a deceptive cadence, forcing the theme to continue. The material of the cadential function reappears with the right- and left-hand parts exchanged in invertible counterpoint at m. 27, and the left hand's scale figure is then shuffled back and forth between the hands

8 Here I am proposing that dominant arrivals may also occur in genuine themes.

9 Bergé and D'hoe employ this term in reference to the resolution to the tonic at the end of the first movement of Beethoven's Tempest Sonata. While I conceive of this passage differently (discussed below with the separated cadence), the spirit of the term as a non-cadential closure on the tonic, intended to parallel Caplin's dominant arrival, is the same. See Bergé, D'hoe, and Caplin (2009, 36, and 36 n52). 


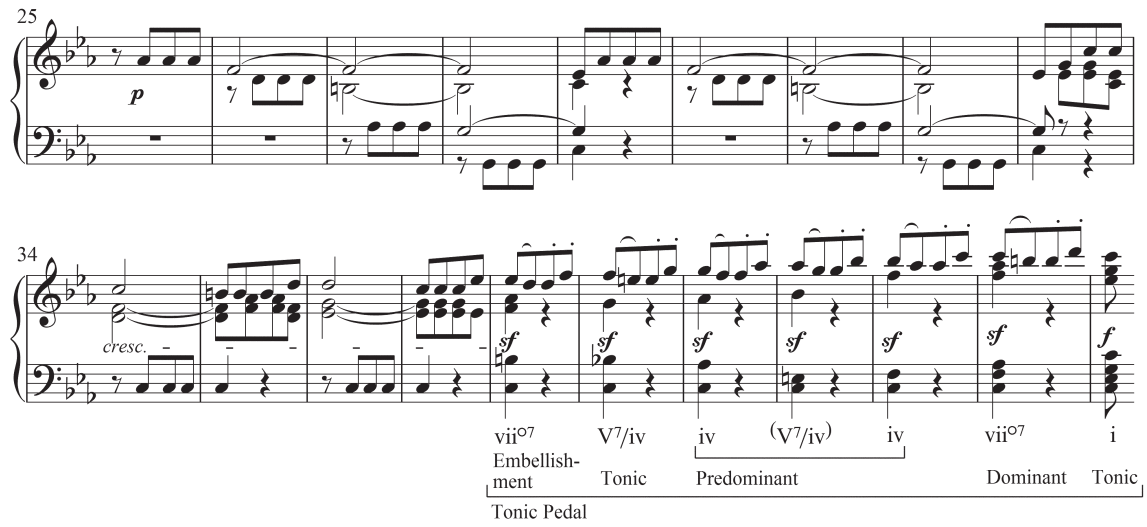

Example 7. Closural function ending the first theme in Beethoven's Fifth Symphony, op. 67, mm. 25-44

until m. 31, where it ends with a final tonic chord. This tonic chord, however, is not approached through a root-position $\mathrm{V}$, but rather through a $\mathrm{V}$ in $\mathrm{m} .30$ that becomes inverted on the last eighth note of the measure. With this subtle but important change to the harmony, the progression cannot be cadential but only cadence-like, and hence the function from m. 27 is closural rather than cadential. Mozart's use of the closural function here is undoubtedly related to the highly imitative texture of this theme (indeed, all the material of the first twenty-seven measures is exchanged between the hands at some point) and consequently its greater emphasis on continuous linear motion rather than a punctuated homophonic texture.

Closural functions occur more frequently in the music of Beethoven, especially in his symphonic music, where homophonic settings are more normative in the classical style. The first movement of the Fifth Symphony provides an excellent example (see example 7). The opening phrase of the famous first theme in mm. 6-21 (not shown) forms a regular antecedent phrase of a period and ends with a half cadence. With the second phrase, however, the tonic note that is reached in the bass at $\mathrm{m} .33$ is retained through the end of the phrase at $\mathrm{m}$. 44. With this insistent tonic pedal, the bass line is unable to articulate an independent harmonic progression, and hence there can be no cadential progression and no cadential function. ${ }^{10}$ But with $\mathrm{m} .38$, the melody fragments into a series of one-measure units and-together with the harmony, which states an expanded form of a full cadence-like progression-produces a closural function. ${ }^{11}$ In particular, this example demonstrates that a closural function can

10 The need for harmonic motion from this tonic pedal is also observed by Burnham $(1995,36)$, who states that, at the end of this phrase, "tonic is again set up as something that must be moved from, rather than toward."

11 Two other of Beethoven's symphonies are worth noting here for their closural functions at the end of the first theme: the Sixth and the Ninth. In the Ninth Symphony, a closural function takes place in mm. 21-27 since the phrase ends with a function supported by the cadence-like progression $\mathrm{i}-\mathrm{iv}-\mathrm{bII}-\mathrm{vii}_{3}^{4}$ (the first two chords of which are prolonged by their respective dominants). The end on the diminished seventh chord acts like a $\mathrm{V}$ chord in a half cadence and thus produces the dominant- 
be expanded with embellishing harmonies in the same manner as a cadential function, in this case with the additions of a vii ${ }^{07}$ chord embellishing the initial tonic, and a prolongation of the predominant with its own dominant.

Because closural functions provide a sense of ending, phrases terminating with a closural function are more akin to those ending with a cadence than those that lack closure altogether-a conception that can influence our perception of classical theme types. ${ }^{12}$ Example 8 shows the opening eight-measure theme from the finale of Mozart's "Hunt" Quartet, K. 458. The first four-measure phrase ends on $\mathrm{V}^{6}$, which is not a cadence because there is an inverted form of V. Rather than lacking closure, however, mm. 3-4 contain a closural function through the cadence-like progression $\left(\mathrm{V}^{6}\right)-\mathrm{I}-\left(\mathrm{I}^{6}-\mathrm{V}_{3}^{4}\right)-\mathrm{V}^{6}$ (parentheses indicate embellishing chords), or more simply I- $\mathrm{V}^{6}$, a progression so similar to a normative half cadence of $\mathrm{I}-\mathrm{V}$ that its effect here, and indeed its formal function, is practically the same as a half cadence: to provide a sense of closure for the first phrase, albeit in a weaker form than a cadence. ${ }^{13}$ Consequently, the theme type seen in this example-Caplin's "compound basic idea + consequent," or hybrid 4 (1998, 61-63) -may be viewed as expressing closure in its compound basic idea, which suggests that a hybrid 4 may simply be a weaker type of period than a distinct structure requiring its own category.

In more complex situations, the repeated substitution of expected cadential functions with closural functions can affect the boundaries of larger sections of a form. In the first movement of Haydn's String Quartet in A Major, op. 20, no. 6, closural functions by means of tonic arrivals form the basis of a musical guessing game that Haydn plays with the listener (see example 9). The first theme of this sonata-form exposition implies another hybrid 4. The entire theme closes in $\mathrm{m}$. 10 with the cadence-like progression $\mathrm{V}_{5}^{6}-\mathrm{I}$, which is a closural function because of the inverted form of V7. Note that the compound basic idea also ends with the same progression in $\mathrm{m}$. 4. When we hear the closural function in $\mathrm{m} .4$, and a repetition of the opening idea in $\mathrm{m} .5$, we expect a consequent phrase to unfold that will have a stronger close than the first phrase. But when we hear essentially the same closural function in m. 8

arrival type of closural function. (Note the standing on the dominant that occurs immediately after this diminished seventh, as though the phrase had ended with a half cadence.) In the Sixth Symphony, mm. 47-53 sound a cadence-like progression of $\mathrm{I}-\mathrm{V}^{7}-\mathrm{I}$ over a tonic pedal that is repeated and fragmented, creating a closural function of the tonic-arrival type. In this case, while the function differs greatly from the Fifth and Ninth in its calm, pastoral character, it is nevertheless structurally similar in its avoidance of true cadential closure.

12 The modern consensus on the definition of a phrase is a span of music that ends with a cadence, a view that originates with Rothstein's $(1989,5)$ assertion that a phrase must include "tonal motion": "A phrase should be understood as, among other things, a directed motion in time from one tonal entity to another; these entities may be harmonies, melodic tones (in any voice or voices), or some combination of the two." Since Rothstein does not preclude non-cadential possibilities, one could understand this definition of a phrase to include not only cadential functions but closural functions as well.

13 See Burstein (2010). In his Appendix 1a, Burstein considers the ending to Mozart's first four measures to be sufficiently similar to a cadence to justify his application of the label "half cadence" (HC). While my terminology differs, it shares with Burstein's the essential function of the progression in this case as a type of close to the four-measure phrase. 


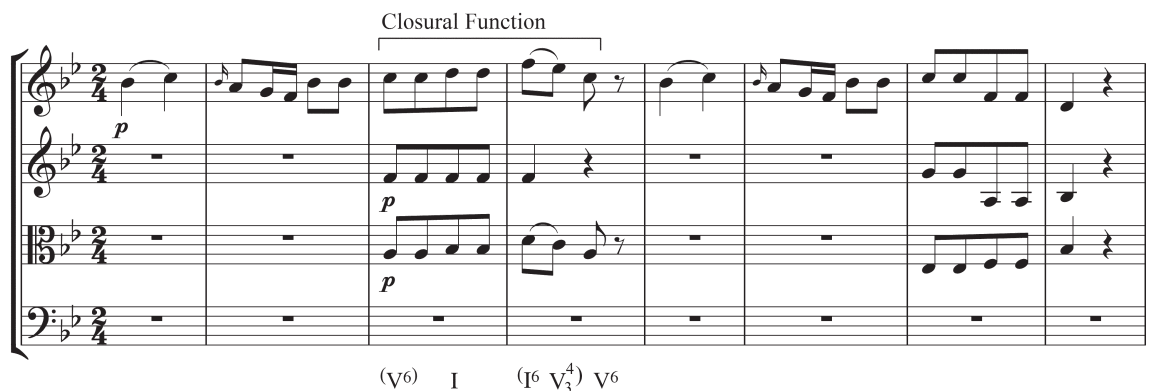

Example 8. Closural function ending the first phrase in Mozart, String Quartet in B-Flat Major, K. 458, "Hunt," IV, mm. 1-8

(which is repeated in mm. 9-10), it sounds as though the second phrase is a varied repetition of the first and not a consequent phrase after all. This reading is reinforced by the fact that the opening idea returns, unusually, for a third time in $\mathrm{m}$. 11. Perhaps this statement will be the expected consequent phrase. ${ }^{14}$ Of course, with typical Haydn wit, it turns out not to be a consequent contained within the first theme, but rather a dissolving consequent that begins the transition, since the music diverges away from the tonic key.

Although most themes in the classical repertoire end with a cadential function, a significant minority end with what I have called a closural function, which may be expressed through either a dominant arrival or a tonic arrival. These non-cadential endings illustrate that closure in classical themes can range from syntactically strong cadential closure to the weaker type of closure offered by closural functions. Moreover, it is no coincidence that, as with most of the examples discussed above, themes ending with closural functions tend to occur within the first-theme group of sonata forms. After all, cadential confirmation of the home key, especially through a perfect authentic cadence, is hardly necessary at this point, since the recapitulation is certain to bring such confirmation with the transposed return of the second-theme group.

\section{The Separated Cadence}

In most cadences, the three components of melody, bass, and inner parts move to the final chord-what Caplin $(1998,43)$ calls the "cadential arrival"- at the same time. This is undoubtedly why many current and past definitions of cadence operate under the assumption that this simultaneous arrival is a feature of all cadences, exceptions occurring only in cases where the melody and/or inner parts are delayed by appoggiaturas. ${ }^{15}$ However, because it is not uncommon

14 In most first themes that are constructed as a period or the period-like hybrid 4, the transition does not begin as a restatement of the first theme's basic idea. Either the first theme closes with a PAC and the transition begins with new material, or it ends with a half cadence and therefore its consequent phrase becomes a "dissolving" one that forms the transition. Haydn's refusal to provide a PAC or a half cadence at the end of the first theme in this example makes it an exceptional case.

15 See, for example, Green $(1979,13-14)$. Green notes that the final tonic chord of an authentic cadence can be delayed by an apparent intervening IV $_{4}^{6}$ chord (the ${ }_{4}^{6}$ voices acting as appoggiaturas to 

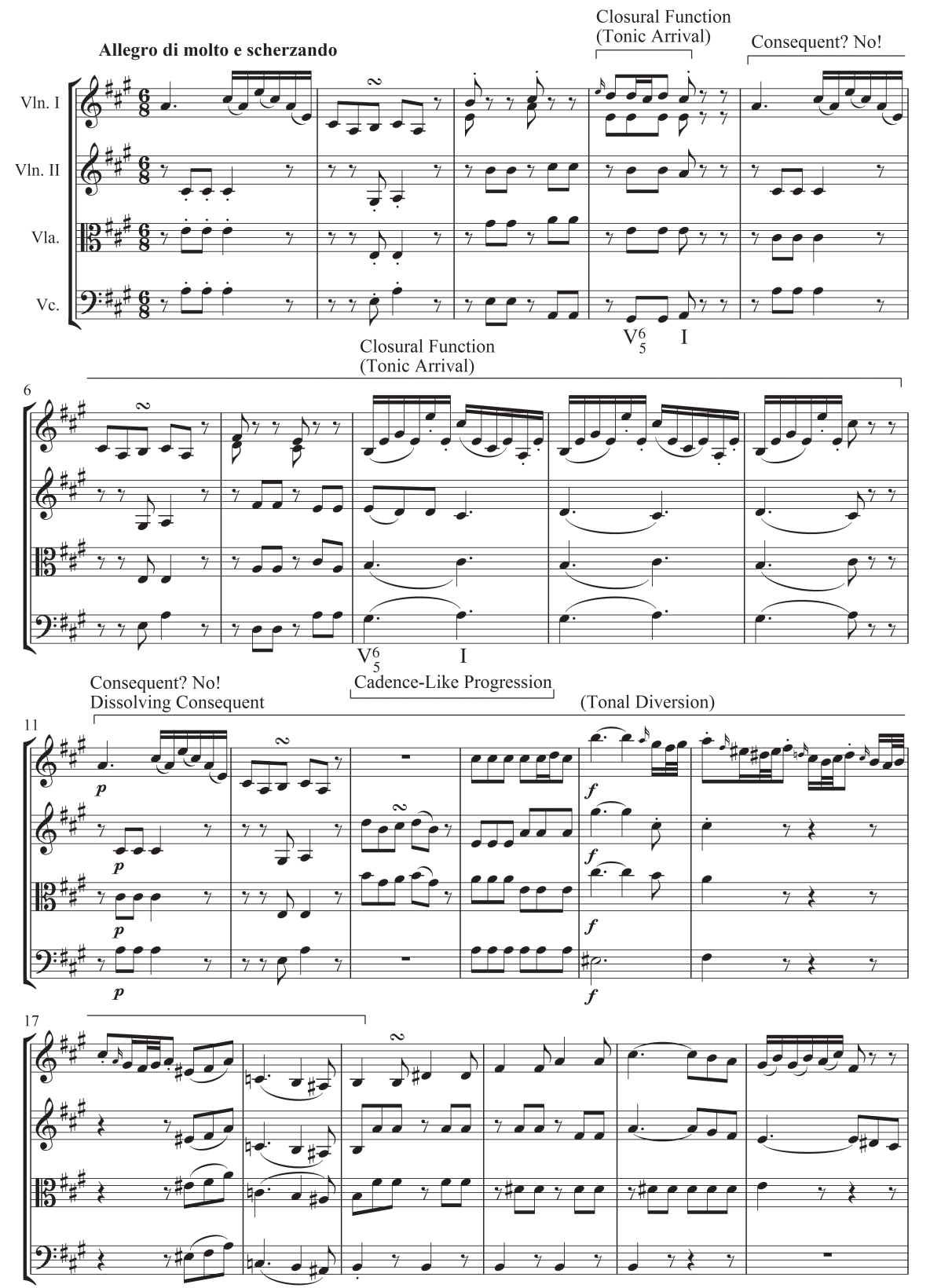

Example 9. Closural function ending the first theme in Haydn's String Quartet in A Major, op. 20 , no. $6, \mathrm{~mm} .1-22$ 
for one or two of a cadence's three components to lag behind and delay completion of the cadential arrival, I propose the term "separated cadence" to describe such situations, of which there are two main types, the "late-melody" and "late-bass."16 A few modest examples will demonstrate the essentials of these techniques before delving into the complexities of a larger-scale application.

The "late-melody separated cadence" occurs when the final melodic note of an authentic cadence sounds after the final bass note due to an intervening chord note, as in the main theme of the slow movement from Mozart's Symphony No. 39, shown in Example 10. Despite the simplicity of this type of separated cadence, it is important to recognize that it is possible for a cadential arrival to be dispersed over a span of music rather than to occur at one particular point, as a result of at least two of its components-melody, bass, and inner parts-arriving at different times.

In other situations, the melody sounds $\hat{3}$ over the last bass note but then moves on to $\hat{i}$ before completing the phrase, blurring the distinction between a perfect and imperfect authentic cadence (PAC and IAC). Example 11a shows a fine instance of this ambiguity in the opening theme of Beethoven's Bagatelle in D Major, op. 33, no. 6, where m. 4 certainly brings a cadential arrival, but whether the cadence is an IAC or a PAC is unclear. Caplin $(1998,58)$ explains, "Since an opening four-measure phrase of a theme does not normally end with full harmonic and melodic closure, we are inclined to believe that this phrase is an antecedent ending with an imperfect authentic cadence. When we perceive that the next phrase is a genuine consequent, closing unambiguously with a perfect authentic cadence, our initial hypothesis of a period design is confirmed. The final D of the antecedent is thus understood to be an embellishment (a 'chordal skip') of the more fundamental melodic note, F\#."

This argument rests on the assumption that an antecedent cannot end with a PAC, because the closure that it provides is too strong. In other words, an antecedent must give the impression that more music will follow, in order to attain a stronger close at the end of the consequent phrase. But PACs may be

the I chord). Kohs $(1973,29)$, likewise states that a final tonic chord may be delayed by appoggiaturas. See also Koch $(1983,40)$, who remarks that "the caesura note of a cadence is at times provided with an overhang." Koch (19) describes a "caesura note" as "that place where a resting point is shown in the melody, that is, the place where one section of the melody can be separated from the following one." Thus, it is clear that, for Koch, the end of a cadence involves the simultaneous sounding of both the melody and bass note. Caplin $(1998,43)$ describes the cadential arrival as "the specific moment in time that marks the structural end of a thematic region." Even Hepokoski and Darcy (2006, 24 and 24n1), who offer a more flexible notion of cadence in their concept of the "medial caesura," agree with Caplin that the cadential arrival is a single point in musical time.

16 The separated cadence is distinct from situations in which the final chord of a cadential arrival is drawn out by a post-cadential function (i.e., a codetta or standing on the dominant). As Caplin indicates, post-cadential functions project the sense of "after-the-end" rather than, say, "prolongingthe-very-end," which would describe the effect of separated cadences. See, for example, Ratner (1980, 45). Ratner shows mm. 43-44 of the first movement of Mozart's String Quartet in C Major, K. 465, and contends that "an overlap is created by dispersing the effect of closure among different voices at different times." This would seem to be the very definition of a separated cadence, but in this case, all three components of the cadence-melody, bass, and inner voices-resolve simultaneously on the downbeat of $\mathrm{m} .43$, completing the cadential arrival. Thus, what Ratner describes as "dispersing the effect of closure" instead falls into the category of a post-cadential function (a codetta). 


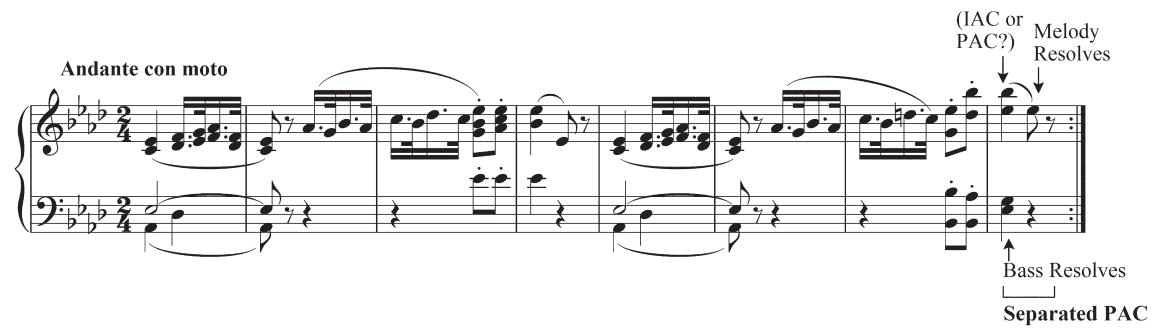

Example 10. "Late-melody" type separated cadence: Mozart, Symphony no. 39 in E-Flat Major, K. 543, II, mm. 1-8

weakened if their component parts resolve at different times. In this case, because the melody ultimately resolves to the tonic degree, the cadence is a PAC, but as this $\hat{1}$ sounds only after the bass and inner parts resolve, it is a separated PAC of the "late-melody" type. Thus, an antecedent may end with a PAC, so long as the hierarchy of closural strength that is fundamental to period form remains intact, that is, if the antecedent's cadence is a separated PAC and the consequent's cadence is a non-separated PAC.

A similar instance of a late-melody separated PAC may be found in the minuet movement of Mozart's String Quartet in A Major, K. 464, shown in example 11b. Here, the opening eight-measure sentence clearly ends with an authentic cadence, but is the cadential melodic note the $\mathrm{C} \#$ or $A$ ? As with the examples above, the pitch at the end of the melodic figure is the decisive factor
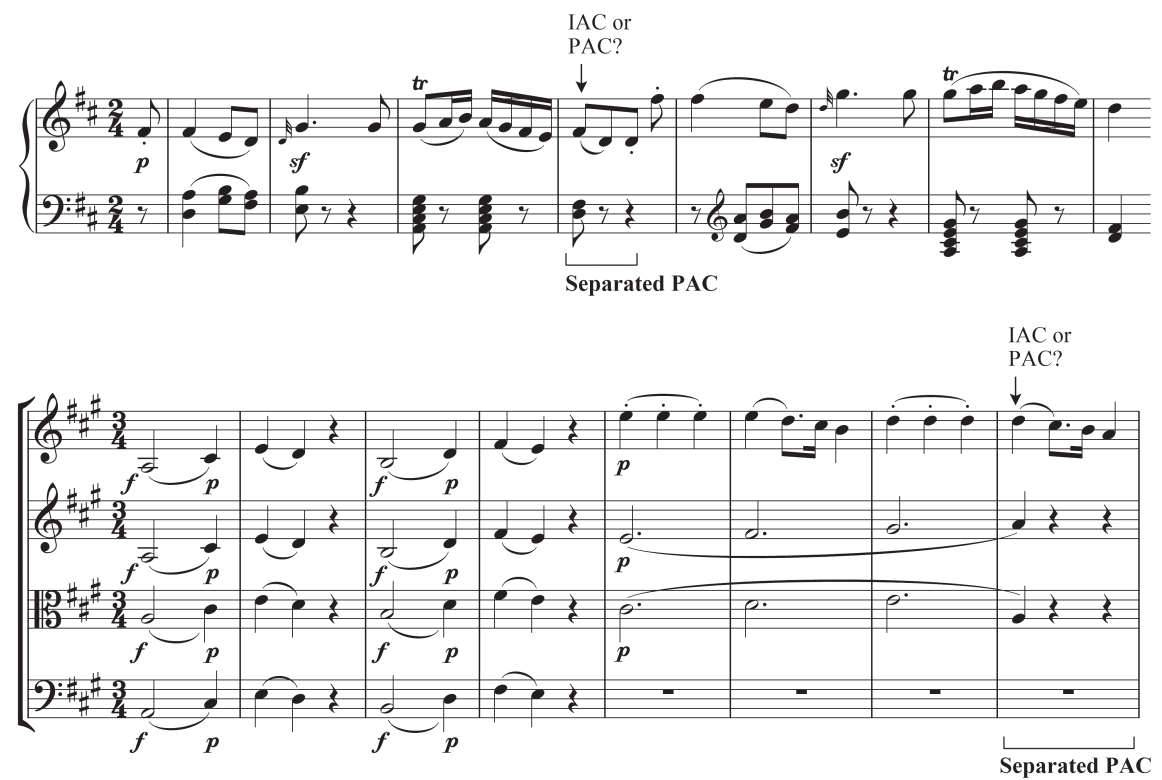

Example 11. Ambiguity between IAC and PAC in "late-melody" type separated cadences

a. Beethoven, Bagatelle in D Major, op. 33, no. 6, mm. 1-8

b. Mozart, String Quartet in A Major, K. 464, II, mm. 1-8 

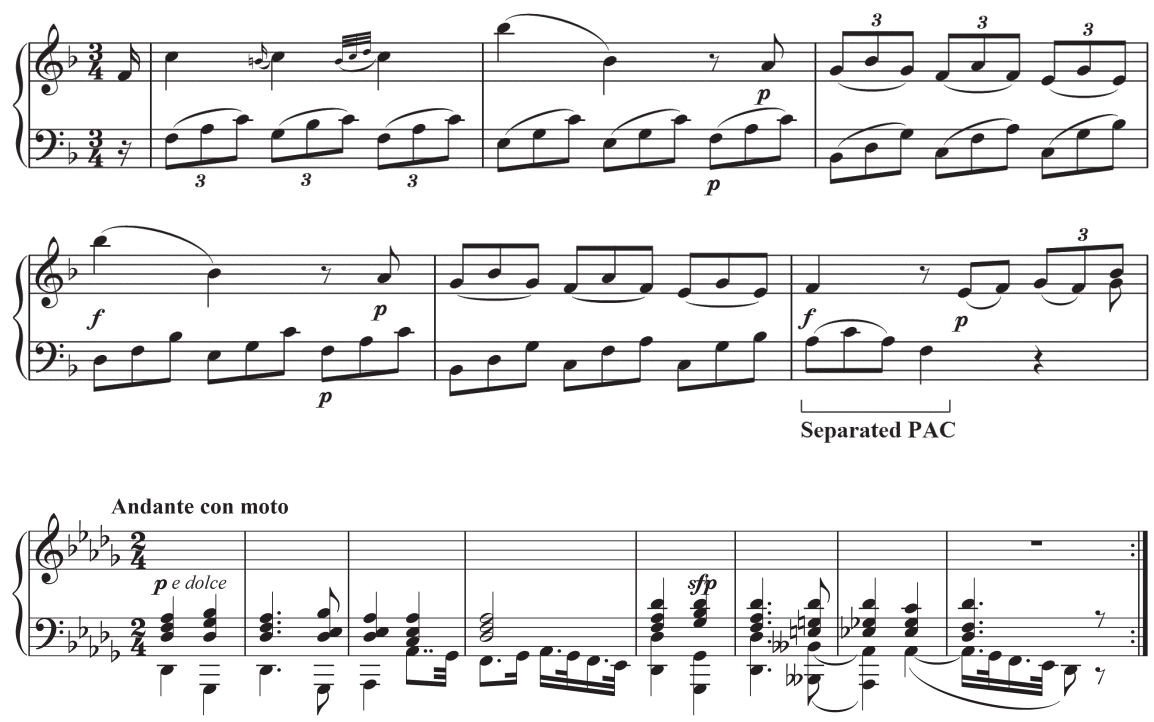

Example 12. "Late-Bass" Type Separated Cadences

a. Mozart, Piano Sonata in C Major, K. 279, II, mm. 1-6

b. Beethoven, Piano Sonata in F Minor, op. 57, “Appassionata," II, mm. 1-8

in determining whether a separated authentic cadence is perfect or imperfect. In this case, the close of the melody on $\hat{i}$ renders the cadence a PAC, albeit one with a weaker sense of closure than a non-separated PAC. ${ }^{17}$

The "late-bass" type of separated cadence occurs in authentic cadences in which the bass voice arrives at $\hat{1}$ only after the melody and inner voices (if present) have resolved to notes in the final tonic harmony. In some cases, this late-arriving bass may result from an arpeggiated tonic chord that ends with $\hat{1}$, as shown in example 12a. More commonly, however, especially in Beethoven, the late-bass type is caused by the bass sustaining $\hat{s}$ (from the cadential V chord) into the tonic harmony, to which the other voices resolve, as demonstrated in example 12b. While there may be little doubt that these instances constitute PACs, they serve as important models for more complex situations in their use of a cadential arrival that is spread across more than a single beat.

A large-scale application of a separated cadence becomes possible when the above techniques appear numerous times in the same cadential arrival, as occurs in the remarkably expansive treatment seen in Beethoven's Tempest Sonata, op. 31, no. 2, at the end of the first movement's exposition. In this passage, the PAC that closes the second theme group-a crucial landmark in sonata form-has been the subject of recent controversy (see example 13a). In

17 Caplin $(1998,265$ n48) admits the possibility that "hearing a perfect authentic cadence here is not out of the question" but ultimately considers this cadence to be an IAC, "since the principal melodic tone in $\mathrm{m} .8$ is C\# (resolving the repeated Ds of the previous measure)." While I agree that the $\mathrm{C} \#$ resolves the previous Ds, I would argue that the tonic note provides such a strong sense of melodic closure that one instead hears a PAC in retrospect once the melody is completed. 


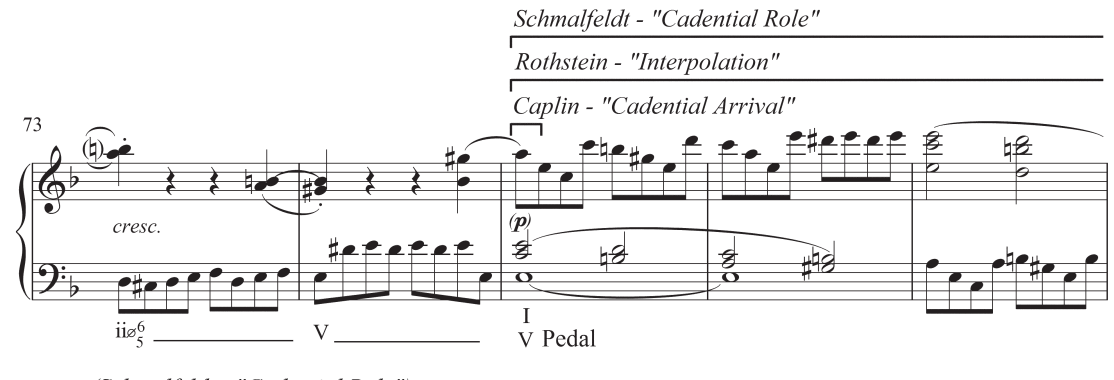

(Schmalfeldt - "Cadential Role")

(Rothstein - "Interpolation")

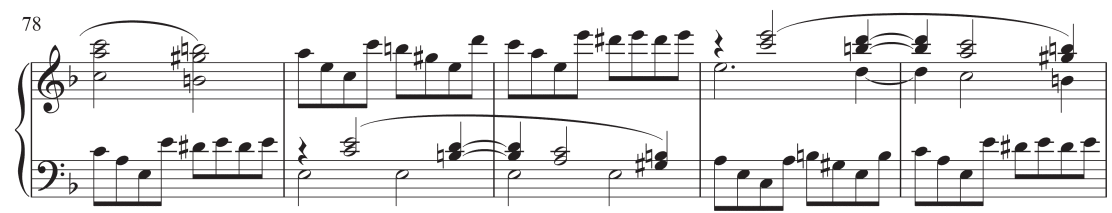

(Schmalfeldt - "Cadential Role")

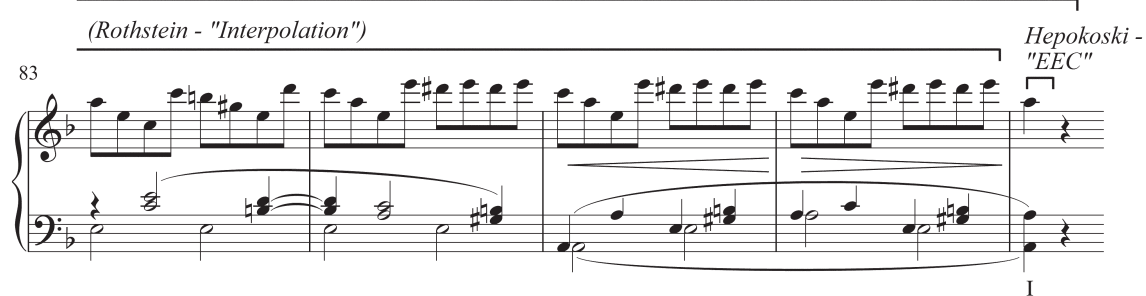

Example 13. The cadence ending the second theme group, in Beethoven, Piano Sonata in D Minor, op. 31 no. 2 (Tempest), mm. 73-87

a. Four theorists' interpretations

a collection of essays on the Tempest Sonata, James Hepokoski (2009a, 200) interprets m. 87 as an EEC, or "essential expositional closure," which is the term he and Warren Darcy employ to designate the cadence closing the second theme group. William Rothstein $(2009,242)$ views $\mathrm{mm}$. $75-86$ as "an interpolation that delays the arrival of the essential expositional closure (EEC)," while Caplin $(2009,114)$ identifies the cadential arrival at m. 75, because "it is here that a genuine cadential dominant (m. 74) resolves to tonic, despite the fact that a literal tonic bass is not present at that moment." Finally, in a celebrated article on the Tempest Sonata, Schmalfeldt (1995, 67-68) views mm. $75-87$ as a series of evaded cadences leading to a closing PAC at m. 87. She concludes, "At this point we may recognize that the entire passage at $\mathrm{mm}$. $75-87$ has served a cadential role."

The major analytical problem in this passage is twofold: not only is there a long dominant pedal in the bass that prevents full resolution at $\mathrm{m}$. 75 but even when the entire passage ends in $\mathrm{m} .87$, the tonic chord is less than satisfying because it lacks the strong preparation of a cadential predominant in 
the preceding progression. ${ }^{18}$ Even if one understands this final tonic as the moment of cadential arrival, what function does the music of mm. 75-86 express? It sits uncomfortably between an incomplete cadential function in $\mathrm{mm}$. 73-74 and the PAC-like resolution to the final tonic in m. 87. Further confusing matters are the partial resolutions that occur at $\mathrm{m}$. 75, where the melody and harmony resolve as expected but the bass remains stubbornly fixed to the dominant note, and at $\mathrm{mm} .85$ and 86 , where the bass and harmony resolve as expected but the melody refuses to close on the tonic.

The function of this passage remains elusive only if we hold firm to the notion that a cadential arrival must occur at a single point in time. But as we have seen with the previous examples, that arrival may take place over a span of music, with different cadential elements resolving at different times. This concept helps to explain the anomalies of the passage, while simultaneously coalescing the seemingly divergent interpretations above into a single viewpoint. Measures 75-87 constitute a separated PAC in which the cadential arrival is spread across these thirteen measures instead of occurring at any one point (see example 13b): at $\mathrm{m}$. 75 , the melody resolves to the tonic note and the harmony resolves to the tonic chord to begin the arrival of the PAC-Caplin's cadential arrival. With the dominant note being sustained in the bass, however, that arrival is extended-by Rothstein's "interpolation"-to m. 85, where it resolves to the tonic along with the harmony. But now the melody avoids complete closure by twice moving to the mediant note, $\hat{3}$, in mm. 85 and 86 . This melodic motion creates the semblance of an IAC, but not a true one, since the cadential arrival has not yet come to an end. It is only when the three elements of melody, bass, and harmony resolve simultaneously at $\mathrm{m} .87$ that the cadential arrival is at last completed-Hepokoski's EEC. Finally, Schmalfeldt's "cadential role" accurately identifies the formal function of the entire separated PAC.

Naturally, such a widely dispersed cadential arrival generates a good deal of ambiguity and is highly unusual, especially at the end of a second-theme group, where a clear PAC is the overwhelming norm in the classical style. But surely this is the point. After all, the blurred cadential effect of this separated PAC is well in keeping with the other ambiguities in the movement's form, such as its famously introductory-sounding first theme. Moreover, similarly expanded treatments of the separated PAC that occupy more than a couple of beats appear in some of Beethoven's other works. ${ }^{19}$ Thus, for Beethoven, the technique seems to have been related to his peculiar penchant for drawing out a dominant bass note across formal boundaries. Striking examples are found at the start of some of his second theme groups (in the first movements of op. 2, no. 1,

18 See also Bergé and D'hoe (2009, 36n51). In reference to the analogous PAC in the recapitulation, the authors remark, "We don't consider the cadential progression in bars 192-193 as an entirely satisfying PAC."

19 See the Hammerklavier Sonata, op. 106, mm. 116-18 (and analogously in the recapitulation in mm. 348-50), and the Piano Sonata in E Minor, op. 9o, II, mm. 253-76, where the dominant bass note twice yields to tonal detours without completing the cadence before regaining the dominant once more in m. 267 and finally resolving it at m. 276 . 

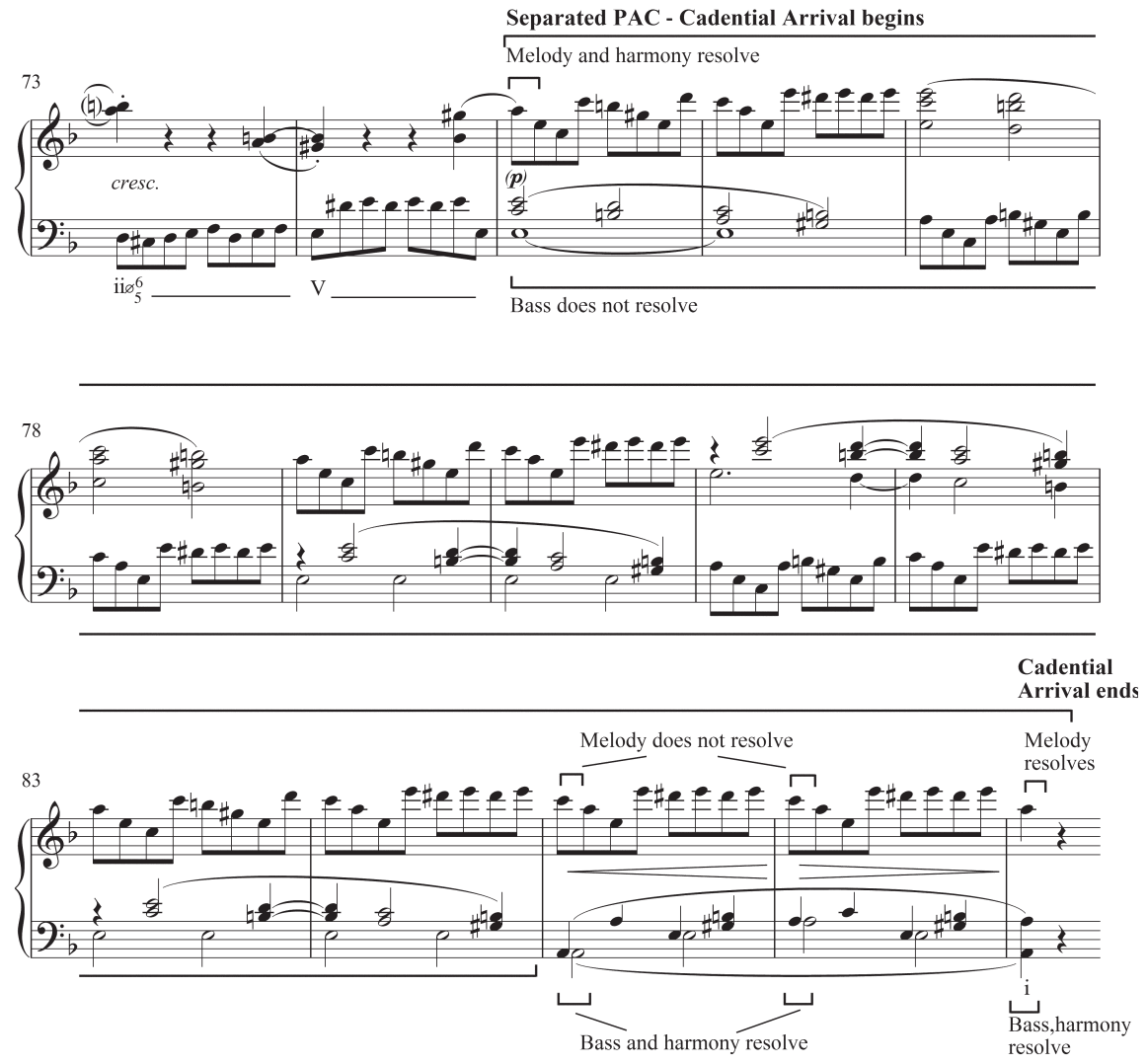

Example 13b. Interpretation as an expansive separated cadence

and the Tempest, among many others) and recapitulations (in the first movements of the Appassionata Sonata and, more briefly, the Eighth Symphony).

While the majority of cadences articulate the moment of cadential arrival through the simultaneous resolution of melody, bass, and inner parts, there are, as we have seen, prominent examples of themes in which these elements are dispersed across a span of musical time. In simpler instances, these separated cadences divide into the two types of "late melody" and "late bass." But the concept can also attain much larger proportions if multiple unsuccessful attempts are made at completing the cadential arrival, as in the Tempest. Finally, although we can still identify separated cadences as PACs, they nevertheless remain a weaker form of cadence than those with a single, unequivocal point of arrival. Thus, the separated cadence is another way in which the closure of a classical theme may be undermined and reduced in its syntactical strength.

\section{Conclusion}

Because the attainment of closure was such a vital aspect of musical form during the classical period, it was a significant preoccupation for composers. 
Consequently, phrases and themes attained a rich diversity of closural options. On the one hand, there were the half and authentic cadences, which were clarified not only through their harmony and location in the phrase, but also by the striking contrasts in melody and texture so characteristic of the classical style. On the other hand, composers sometimes sought to weaken or obfuscate the close of a phrase by using alternatives to the cadence (in addition to other types of cadential avoidance such as deceptive, evaded, or abandoned cadences). I have described one of these as a "closural function," which mimics the sound of a cadential function through a cadence-like progression, and another as the "separated cadence," which transforms the cadential arrival from a single moment in time into a broader span of music. While both of these alternatives are far less common than true cadences at the end of themes, their appearance demonstrates that a cadence was not an absolute requirement for thematic closure in the classical style. Thus, closure in classical music is a highly complex issue, one that requires a wider range of analytical tools than we currently employ if we are to gain a deeper and more complete understanding of this continually fascinating repertoire.

\section{WORKs Cited}

Bergé, Pieter, and Jeroen D’hoe. 2009. “To Play or Not to Play: Motivic Connections in the First Movement of Beethoven's Tempest Sonata." In Bergé, D'hoe, and Caplin 2009, 9-37.

Bergé, Pieter, Jeroen D’hoe, and William E. Caplin, eds. 2009. Beethoven's Tempest Sonata: Perspectives of Analysis and Performance. Walpole, MA: Peeters.

Burnham, Scott. 1995. Beethoven Hero. Princeton: Princeton University Press. Burstein, L. Poundie. 2010. "Half, Full, or in Between? Distinguishing Half and Authentic Cadences." Paper presented at the annual meeting of the Society for Music Theory, Indianapolis, Indiana, 6 November.

Caplin, William E. 1987. “The 'Expanded Cadential Progression': A Category for the Analysis of Classical Form." Journal of Musicological Research 7:215-57.

—. 1991. "Structural Expansion in Beethoven's Symphonic Forms." In Beethoven's Compositional Process, edited by William Kinderman, 27-54. Lincoln: University of Nebraska Press in association with the American Beethoven Society and the Ira F. Brilliant Center for Beethoven Studies, San José University.

-1998. Classical Form: A Theory of Formal Functions for the Instrumental Music of Haydn, Mozart, and Beethoven. New York: Oxford University Press.

-2004. "The Classical Cadence: Conceptions and Misconceptions." Journal of the American Musicological Society 57:51-117.

- 2009. "Beethoven's Tempest Exposition: A Springboard for Form-Functional Considerations.” In Bergé, D’hoe, and Caplin 2009, 87-125.

Clendinning, Jane Piper, and Elizabeth West Marvin. 2011. The Musician's Guide to Theory and Analysis. 2nd ed. New York: W. W. Norton. 
Green, Douglass M. 1979. Form in Tonal Music: An Introduction to Analysis. 2nd ed. New York: Holt, Rinehart and Winston.

Hepokoski, James. 2009a. “Approaching the First Movement of Beethoven's Tempest Sonata through Sonata Theory." In Bergé, D’hoe, and Caplin 2009, 181-212.

. 2009b. "Comments on William E. Caplin's Essay 'What Are Formal Functions?"' In Musical Form, Forms \& Formenlehre, ed. Pieter Bergé, 41-5. Leuven: Leuven University Press.

Hepokoski, James, and Warren Darcy. 2006. Elements of Sonata Theory: Norms, Types, and Deformations in the Late-Eighteenth-Century Sonata. New York: Oxford University Press.

Koch, Heinrich Christoph. 1983 [1787]. Introductory Essay on Composition: The Mechanical Rules of Melody, Sections 3 and 4. Translated by Nancy Kovaleff Baker. New Haven: Yale University Press.

Kohs, Ellis B. 1973. Musical Form: Studies in Analysis and Synthesis. Boston: Houghton Mifflin.

Kostka, Stefan, and Dorothy Payne. 200o. Tonal Harmony. 4th ed. New York: McGraw-Hill.

Ratner, Leonard G. 1980. Classic Music: Expression, Form, and Style. New York: Schirmer Books.

Ratz, Erwin. 1973. Einführung in die musikalische Formenlehre. 3rd ed. Vienna: Universal Edition.

Rothstein, William. 1989. Phrase Rhythm in Tonal Music. New York: Schirmer Books.

—_ 2009. "Riding the Storm Clouds: Tempo, Rhythm, and Meter in Beethoven's Tempest Sonata." In Bergé, D’hoe, and Caplin 2009, 235-71.

Schmalfeldt, Janet. 1992. "Cadential Processes: The Evaded Cadence and the 'One More Time' Technique." Journal of Musicological Research 12:1-52.

—_ 1995. "Form as the Process of Becoming: The Beethoven-Hegelian Tradition and the 'Tempest' Sonata." Beethoven Forum 4:37-71.

_ 1997. "Coming to Terms: Speaking of Phrase, Cadence, and Form." In Theory Only 13:95-115.

Schoenberg, Arnold. 1967. Fundamentals of Musical Composition, edited by Gerald Strang. New York: St. Martin's Press.

Webster, James. 1991. Haydn's "Farewell" Symphony and the Idea of Classical Style. New York: Cambridge University Press.

\begin{abstract}
This article challenges two of William E. Caplin's basic precepts regarding cadences in the classical style. First, the author argues that melody and texture contribute to the onset of cadential function. Second, he contends that themes may end not only with a half or authentic cadence, but also with a "closural function", which substitutes for cadential function through a "cadence-like progression". Moreover, he discusses how a theme may end with a cadence such that its melody and bass resolve at different times, a phenomenon he calls the separated cadence.
\end{abstract}




\section{RÉSUMÉ}

Cet article remet en question deux des postulats de base William E. Caplin concernant les cadences dans le style classique. Tout d'abord, l'auteur fait valoir que la mélodie et la texture aident à délimiter la fonction cadentielle. Il soutient ensuite que tant la demicadence que la cadence authentique peuvent marquer la fin d'un thème, tout comme peut le faire une "fonction conclusive", qui se substitue à la fonction cadentielle par une "progression quasi cadentielle». En outre, il explique comment une cadence peut conclure un thème de telle sorte que sa mélodie et sa basse se résolvent à différents moments, un phénomène qu'il appelle la cadence séparée. 